\title{
Exceptionally High Ni Concentration in Phloem of Roots of Nickel- hyperaccumulating Berkheya zeyheri subsp. rehmannii var. rogersiana
}

\author{
J Mesjasz-Przybylowicz¹, AD Barnabas ${ }^{1}$, and WJ Przybylowicz ${ }^{\mathbf{1}, 2}$ \\ 1. Materials Research Department, iThemba LABS, National Research Foundation, P O Box 722, \\ Somerset West, South Africa \\ 2. AGH University of Science and Technology, Faculty of Physics \& Applied Computer Science, al. \\ A. Mickiewicza 30, Krakow, Poland
}

Hyperaccumulation is an unusual plant response to metaliferous soils. Such soils, like those derived from ultramafic rocks, are characterized by elevated concentrations of heavy metals including $\mathrm{Ni}, \mathrm{Cr}$, $\mathrm{Zn}$ and $\mathrm{Cd}$. Most of the plants growing on these metal-rich soils exclude metals from their shoots as excessive accumulation of heavy metals is toxic to the majority of plants. However, about $2 \%$ of plants on metaliferous soils take up and accumulate large quantities of metals in their shoots: a phenomenon known as hyperaccumulation. In a previous study [1] significantly higher concentrations of $\mathrm{Ni}$ were found in leaves of the Ni-hyperaccumulator, Berkheya zeyheri subsp. rehmannii var. rogersiana compared to those of its non-hyperaccumulating counterpart Berkheya zeyheri subsp. rehmannii var. rehmannii. The present study is an extension of the previous one and compares the distribution and concentration of $\mathrm{Ni}$, as well as other elements, in the roots of the two varieties. The Ni-hyperaccumulator $(\mathrm{H})$ was collected from Songimvelo Game Reserve and the nonhyperaccumulator (NH) from Agnes Mine, Mpumalanga, South Africa.

Roots were sampled in the root hair region. To correlate elemental distribution with anatomical features, samples were processed for anatomical studies using standard resin-embedding procedures. Elemental distribution and concentration were determined using a nuclear microprobe on root samples parallel to those taken for anatomy. These were sectioned, cryofixed and subsequently freeze-dried. Two complementary techniques, particle induced X-ray emission (PIXE) and proton backscattering (BS) were performed simultaneously. Anatomical features of roots of the $\mathrm{H}$ and $\mathrm{NH}$ are shown in Fig.1a and d respectively. Tissue composition is similar except that in the cortex of the $\mathrm{H}$ sclereids are also present (Fig.1a). Average concentrations of selected elements in the analyzed cross sections are given in Table 1 and representative distribution maps of $\mathrm{Ni}$ and $\mathrm{Ca}$ are shown in Fig.1b,c,e,f. The average Ni concentration was significantly higher in the $\mathrm{H}(6430 \mathrm{mg} / \mathrm{kg}$; ca. 35 times higher) compared to the NH (Table 1). The highest Ni enrichment (up to $2.5 \mathrm{wt} . \%$ ) occurred in the phloem of the $\mathrm{H}$ (Fig.1b) with lower enrichment in tissues contiguous with it and in the cortex (Fig.1b). In contrast in the NH, the average Ni concentration was significantly lower $(180 \mathrm{mg} / \mathrm{kg}$, Table 1) with the highest Ni enrichment external to the cortex in the exodermis/epidermis and root hairs (Fig.1e). The average concentration of $\mathrm{Ca}$ was higher in the $\mathrm{H}$ (1.75 wt.\%, Table 1) compared to the NH (1.56 wt.\%, Table 1). The highest $\mathrm{Ca}$ enrichment areas in the $\mathrm{H}$ mirrored those of $\mathrm{Ni}$ (phloem, tissues contiguous with the phloem and cortex, Fig.1c) while in the NH this was confined mainly to the exodermis/epidermis with lower $\mathrm{Ca}$ enrichment in the cortex and root hairs (Fig.1f). With regard to the other main nutrient elements, the average concentration of $\mathrm{K}$ and $\mathrm{S}$ was higher in the $\mathrm{H}$ compared to the NH while the average concentration of $\mathrm{P}$ was higher in the NH (Table 1). K enrichment was restricted mainly to the cortex in both varieties and $\mathrm{S}$ and $\mathrm{P}$ to tissues in close association with the phloem (endodermis and vascular cambium) in the $\mathrm{H}$ and $\mathrm{NH}$. Minor or trace elements ( $\mathrm{Fe}, \mathrm{Cu}, \mathrm{Zn}$ ) were confined to the outermost tissues (epidermis/exodermis) in both varieties.

The extremely high concentration of $\mathrm{Ni}$ in the phloem of the $\mathrm{H}$ suggests that this tissue may be involved in Ni transport. The known high mobility of $\mathrm{Ni}$ in the phloem would enhance such a role 
[2]. $\mathrm{Ca}$ is also concentrated in the phloem tissues indicating possible co-distribution with Ni. This would be of relevance as it has been shown that $\mathrm{Ni}$ is able to use $\mathrm{Ca}$ transport proteins to facilitate its uptake and movement in plants [3].

\section{References:}

[1] J Mesjasz-Przybylowicz et al, Microscopy and Microanalysis (2010), http://www.microscopy.org/MandM/2010/barnabas.pdf.

[2] V Page, L Weisskopf and U Feller, New Phytologist 171(2006), p. 329-341.

[3] J Antonovics, A D Bradshaw and R G Turner, in "Heavy metal tolerance in plants: advances in ecological research”, ed. J B Cragg, (Academic Press, London) 1971, p.1-85.

Table 1. Average concentrations of selected elements $(\mathrm{mg} / \mathrm{kg})$ in roots of Berkheya zeyheri var. rogersiana $(\mathrm{H})$ and Berkheya zeyheri var. rehmannii $(\mathrm{NH})$.

\begin{tabular}{cccccccccccccc}
\hline Root & $\mathrm{P}$ & $\mathrm{S}$ & $\mathrm{Cl}$ & $\mathrm{K}$ & $\mathrm{Ca}$ & $\mathrm{Ti}$ & $\mathrm{V}$ & $\mathrm{Cr}$ & $\mathrm{Mn}$ & $\mathrm{Fe}$ & $\mathrm{Ni}$ & $\mathrm{Cu}$ & $\mathrm{Zn}$ \\
\hline $\mathrm{H}$ & 240 & 13630 & 4200 & 80200 & 17500 & 1320 & 85 & 790 & 220 & 44700 & 6430 & 180 & 80 \\
& $(43)$ & $(570)$ & $(90)$ & $(800)$ & $(240)$ & $(40)$ & $(16)$ & $(20)$ & $(40)$ & $(700)$ & $(140)$ & $(17)$ & $(7)$ \\
\hline $\mathrm{NH}$ & 550 & 3760 & 15460 & 62900 & 15620 & 490 & 44 & 340 & 420 & 20800 & 180 & 37 & 113 \\
& $(40)$ & $(160)$ & $(270)$ & $(440)$ & $(190)$ & $(15)$ & $(10)$ & $(13)$ & $(30)$ & $(390)$ & $(9)$ & $(4)$ & $(7)$ \\
\hline
\end{tabular}
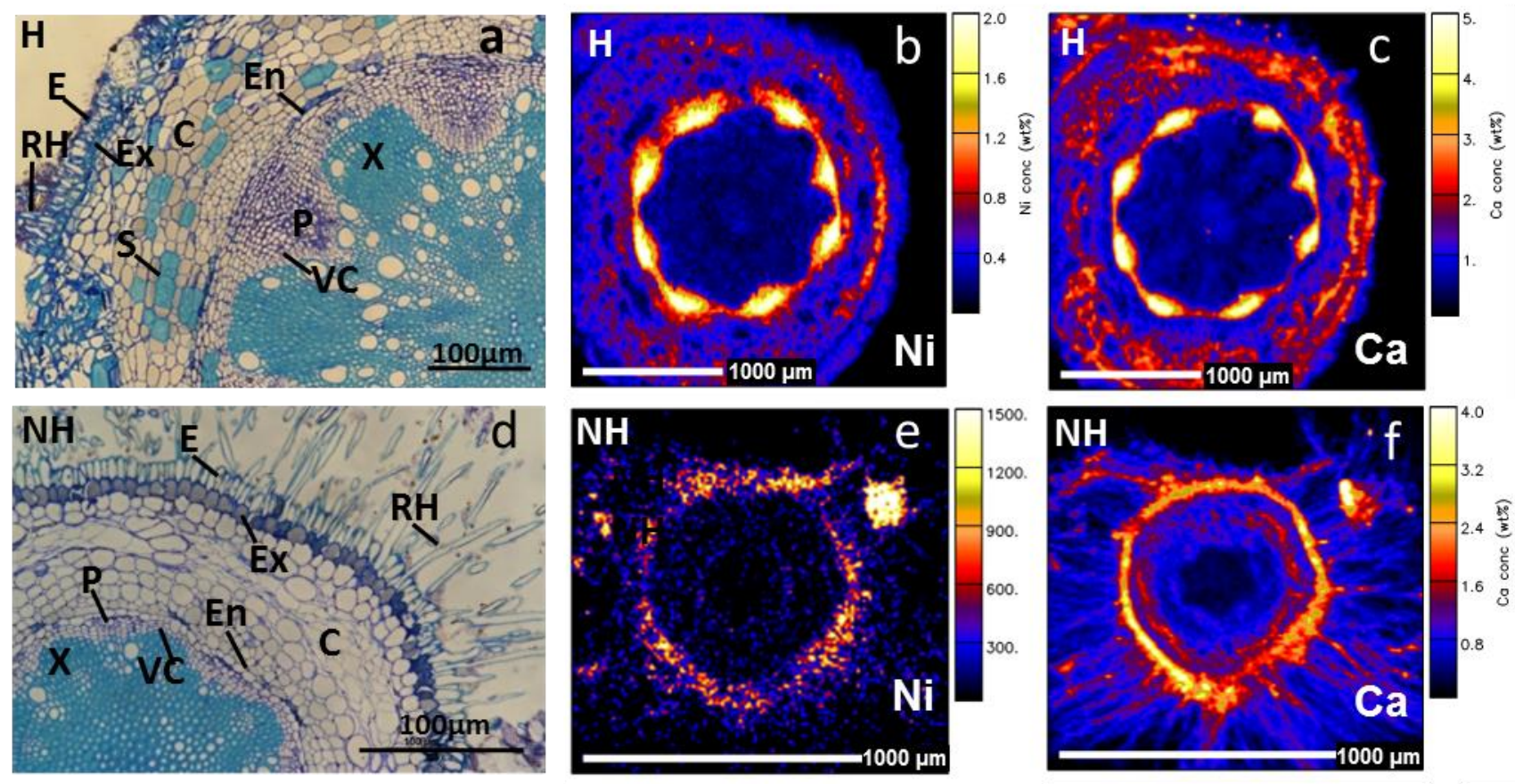

Figure 1. Light micrographs of anatomical features (a,d) and quantitative elemental maps of Ni and $\mathrm{Ca}$ distribution in root sections of Ni-hyperaccumulating $(\mathrm{H})$ and non-hyperaccumulating $(\mathrm{NH})$ varieties of Berkheya zeyheri. Concentration scale in wt.\% (b,c,f) or in $\mathrm{mg} / \mathrm{kg}$ (e). C,cortex; E,epidermis; Ex,exodermis; P, phloem; RH, root hair; S, sclereids; VC, vascular cambium; X, xylem. 